\section{Best Paper Award 2017}

The Canadian Journal of Earth Sciences "Best Paper Award" is an annual award given jointly by Canadian Science Publishing (CSP) and the Geological Association of Canada. It reflects the Geological Association of Canada's selection of the Canadian Journal of Earth Sciences as the "principal medium of publication of scientific papers". This award is designed to: (1) attract excellent papers to the journal; (2) acknowledge and give credit to excellence in geoscience research; and (3) unite the Geological Association of Canada and the Canadian Journal of Earth Sciences in their common goal of promoting Canadian geoscience.

It is a great pleasure for me to announce that the winner of the prestigious 2017 GAC-CSP Canadian Journal of Earth Sciences Best Paper Award is:

Tiffani A. Fraser and Matt P. Hutchison. 2017. Lithogeochemical characterization of the Middle-Upper Devonian Road River Group and Canol and Imperial formations on Trail River, east Richardson Mountains, Yukon: age constraints and a depositional model for fine-grained strata in the Lower Paleozoic
Richardson trough. Canadian Journal of Earth Sciences, 54(7): 731-765. doi:10.1139/cjes-2016-0216.

I extend my congratulations to Tiffani A. Fraser and Matt P. Hutchison on this achievement and encourage all to read this fascinating paper. I would also like to thank the authors for publishing their excellent work in the Canadian Journal of Earth Sciences.

Fraser and Hutchison (2017) presents a detailed investigation of the lithological, stratigraphic, and geochemical characteristics of the Middle-Upper Devonian Road River Group, Canol Formation and Imperial Formation in the Richardson Mountains, Yukon. The authors integrate the new and published data to propose a new comprehensive depositional model for the Richardson trough in the Middle and Late Devonian.

I would like to thank Tiffani A. Fraser and Matt P. Hutchison for submitting their work to the Canadian Journal of Earth Sciences.

\author{
Ali Polat \\ Editor \\ Canadian Journal of Earth Sciences
}

